\title{
AVASCULAR NECROSIS OF STAPES CRURA IN ONE CASE OF OPERATED OTOSCLEROSIS
}

\author{
Milan Erdoglija ${ }^{1}$, Jelena Sotirovic ${ }^{1}$, Violeta Jacimovic ${ }^{1}$, Biserka Vukomanovic ${ }^{2}$ \\ Department of Otorhinolaryngology, Otology Unit, Military Medical Academy, Belgrade, Serbia ${ }^{1}$; Institute of Pathology, \\ Military Medical Academy, Belgrade, Serbia ${ }^{2}$
}

Summary: Unilateral otosclerosis combined with avascular necrosis of stapes crura is a rare entity. It should be considered in a case of high grade otosclerosis. Symptoms are the same as in patients who suffer from common otosclerosis. Patients complain on progressive hearing loss and tinnitus. The diagnosis is made clinically by conventional audiologic evaluation and radiologically by x-ray mastoid Schuller's view and CT scan. HRCT scan makes visible all parts of ossicular chain and gives surgeon some information about ossicular chain damage. Surgery with stapedotomy and stapes prosthesis implantation in a case of otosclerosis with avascular necrosis of stapes crura can be success therapy to improve patient's hearing

Key words: Otosclerosis; Avascular necrosis; Stapes crura; Hearing loss; Tinnitus; Pure-tone audiometry; Tympanometry; Stapedotomy

\section{Introduction}

Otosclerosis is a special progressive bone remodeling disorder restricted to the otic capsule, following with stapes fixation and resulting in conductive hearing loss and tinnitus. Etiopathogenesis of otosclerosis is controversial. The uncontrolled and increased osteoid turnover results in osteolytic foci with sharply defined, irregular margins, mostly in the anterior pole of the stapes footplate. The disease leads to stapes fixation and conductive deafness through many years. Otosclerosis usually begins in teenage period of life, develops bilateral (70-80\%), two times more frequently in female population and leads to severe deafness in the 5th decade (2). There is mild hearing loss in the beginning off this illness with thickened stapes footplate (grade I otosclerosis). Histological appearance of otosclerosis is characterized by hypervascularized focus filled with numerous multinucleated osteoclasts, hypercellular fibrous stroma and plump, distorted osteoblasts. The process develops to severe deafness after many years and finishes with endstage or grade IV otosclerosis corresponding to a remodeled lamellar bone structure with hypocellularity or acellularity on wide pseudo-vascular spaces of bones $(1,2)$. The diagnosis of otosclerosis can be established by clinical examination, hearing tests and radiological findings. Anamnesis must be sufficient and precisely. Otoscopy and otomycroscopy examination is normal in patients with otosclerosis. Pure tone audiometry shows conductive or mixed hearing loss. Tympanometry is mostly normal and acoustic stapedial reflex is absent in patients with otosclerosis. X-ray mastoid Schuller's view shows normally pneumatized mastoid air cells in patients with otosclerosis. Surgery is the only therapeutic treatment for otosclerosis. Stapedotomy with stapedial prosthesis is most successful surgery preformed nowadays.

Avascular necrosis is a bones disease resulting from the temporary or permanent loss of the blood supply to the bones. There are no oxygen and nutrition for bone tissue. Bone tissue collapse and dies in area without blood supplying. Avascular necrosis of the bone tissue leads to pathological fractures of the bone. There are many causes of avascular necrosis such as alcoholism, excessive steroid use, trauma, Caisson disease (decompression sickness), osteogenesis imperfecta, vascular compression, hypertension, vasculitis, thrombosis, radiation, bisphosphonates (particularly in the mandible) (11) and (very rarely) sickle cell anaemia. Avascular necrosis can happen in any bone, it may affect just one bone, more than one bone at the same time, or more than one bone at different times, almost in ages $30-50$ years. Clinical avascular necrosis most commonly affects the ends (epiphysis) of long bones such as the femur and humerus or joints of the hip, knee, and shoulder. Avascular necrosis is rare entity for other bones, including bones in the middle ear. There are tree little bones in the middle ear (malleus, incus and stapes) which are not long bones. There were many described cases of avascular necrosis of long process of the incus caused by poor blood supply which was a result of different kind of pathological process or result of stapes prosthesis $(3,12)$. Avascular necrosis of stapes crura potentially can happen as it happens with long bones femur or humerus, for example. There are no articles about avascular necrosis of stapes crura. Displacement of stapes crura is described in some other pathology process like congenital anomalies, chronic suppurative otitis media, cholesteatoma etc. Fracture of stapes crura occurs rarely, following head injures, isolated or associated with temporal bone fractures (15). 


\section{Case report}

37-year-old male patient was admitted in Clinic for ear, nose and throat at the Military Medical Academy because of evaluation of hearing loss and tinnitus on his right ear. He has been suffering from progressive hearing loss and tinnitus on his right ear for 15 years, which became especially deteriorated during the year before his admission. He noticed that his hearing was temporarily better during Valsalva test. He has never had previous injures of the head or ear, ear pain or ear infection and vertigo as well. He was in good physical condition, without some systemic diseases. There was no evidence of problems with some other bones previously. He was not in a habit of smoking or drinking alcohol. There were no cases of otosclerosis in his family. Patient did not show any risk factors for avascular necrosis at all.

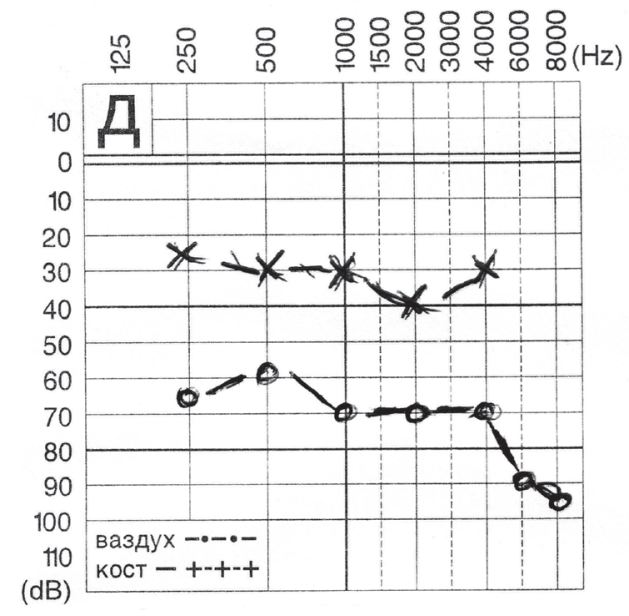

Fig. 1: Pure-tone audiometry before surgery - mixed hearing loss on the right ear

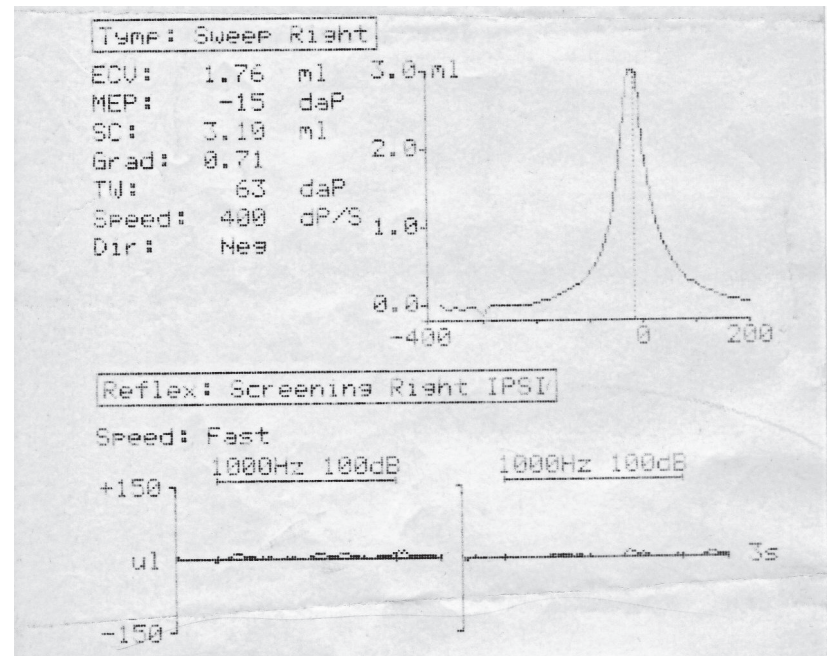

Fig. 2: Tympanometry test on right ear is Ad and acoustic stapedial rexlex is absent
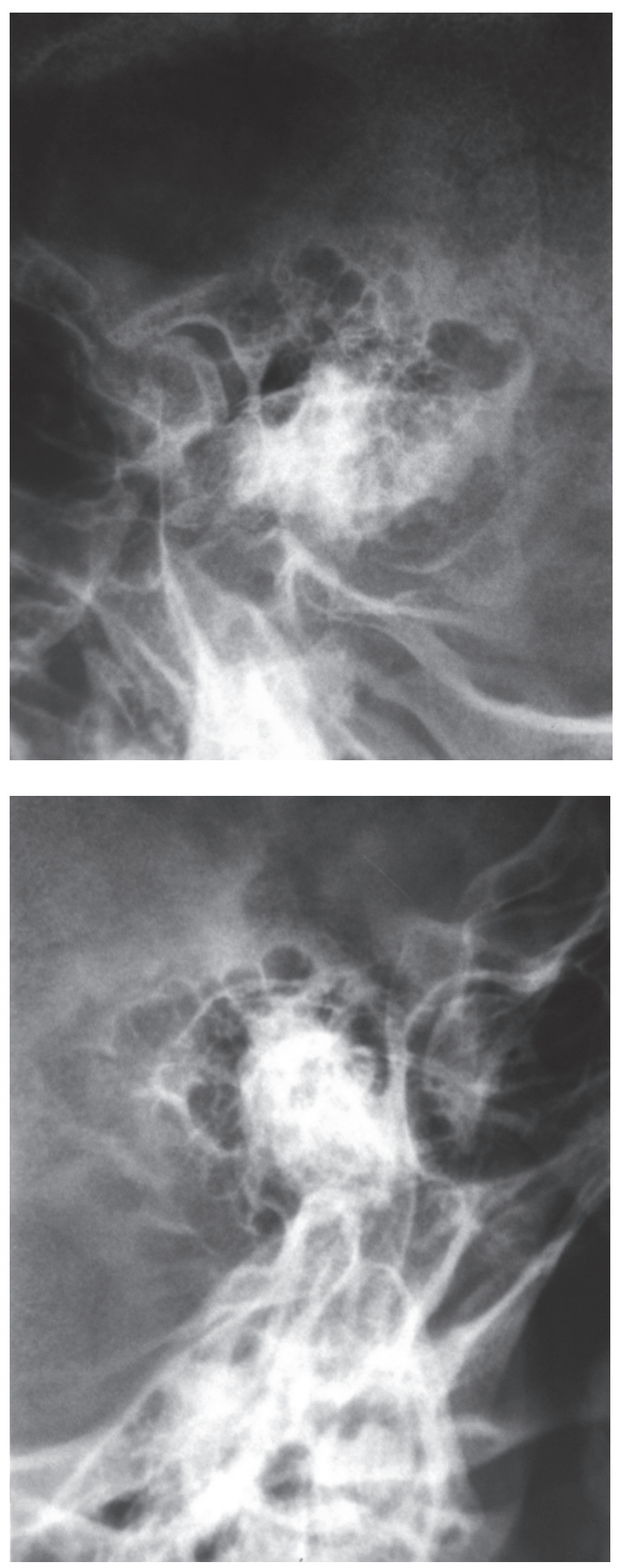

Fig. 3: X-ray mastoid Schuller's view - well developed normally pneumatized mastoid air cells on both side 
Clinical findings which consisted of detailed anamnesis and conventional audiologic evaluation were typical for unilateral otosclerosis. Otoscope examination was normal on both ears. Pure-tone audiometry showed profound mixed hearing loss on his right ear (Fig. 1) and mild sensorineural hearing loss on his left ear in high frequencies between 6 and $8 \mathrm{kHz}$ to the $80 \mathrm{~dB}$. Tympanometry tests were normal on both ear, but one tympanogram was Ad on the right ear in one previous tympanometry examination (Fig. 2). Acoustic stapedial reflex was absent on his right ear (Fig. 2) and present on his left ear on ipsi lateral stimulation. X-ray mastoid Schuller's view showed well-developed normally pneumatized mastoid air cells on both side (Fig. 3). Blood tests showed normal result. After all preoperational examinations, we preformed surgery under general anesthesia. Intra operatively we found the following:

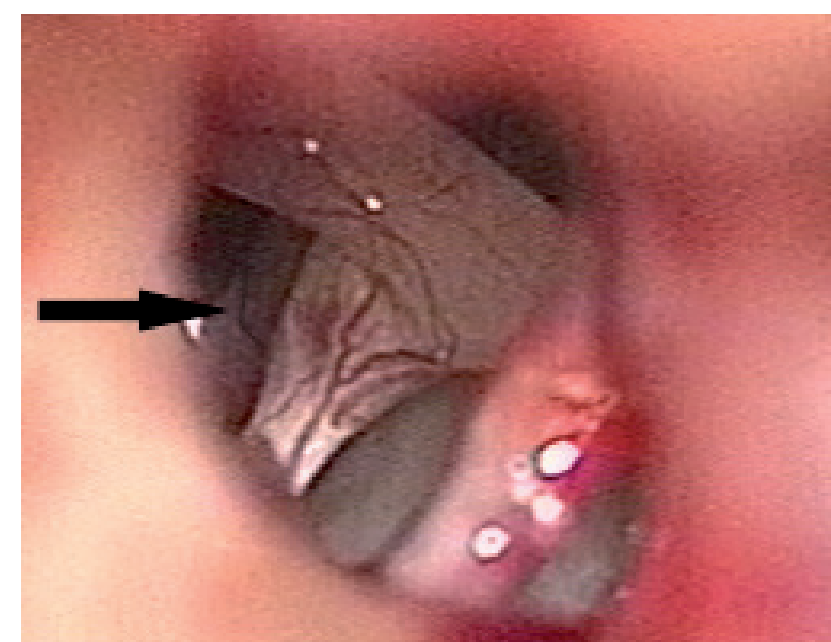

Fig. 4: Intra operatively view - arrow shows the point of displacement of stapes crura

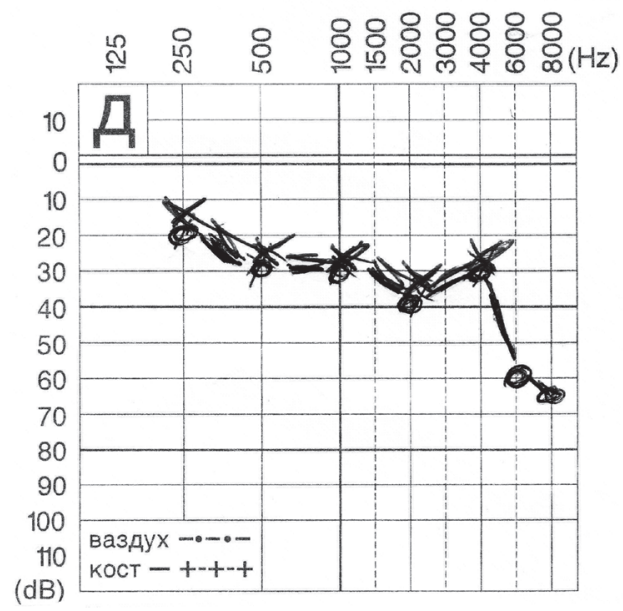

Fig. 6: Pure-tone audiometry after surgery-closed gap in the right ear
We performed end aural approach. Indirect mobility of ossicular chain was good- touching manubrium of malleus we could see mobility of long processus of incus. Direct mobility of ossicular chain- touching suprastructure of stapes, we could not performed, because of break of stapes crura (Fig. 4). Ankylosis of thick stapes footplate and stapedovestibular joint immobility was found touching stapes footplate by nidle instrument, caused by osteosclerotic process. Then stapedial tend was cut. Incudostapedial joint was disarticulated and stapes suprastructure was removed. Instrumental stapedotomy was performed. K-Piston titanium prosthesis $5.25 \times 0.4 \mathrm{~mm}$ was implanted. Autologous fibrous tissue was used to stabilize prosthesis. Direct and indirect mobility of ossicular chain after prosthesis implantation was good. Stapes suprastructure was analyzed histologically (Fig. 5) and
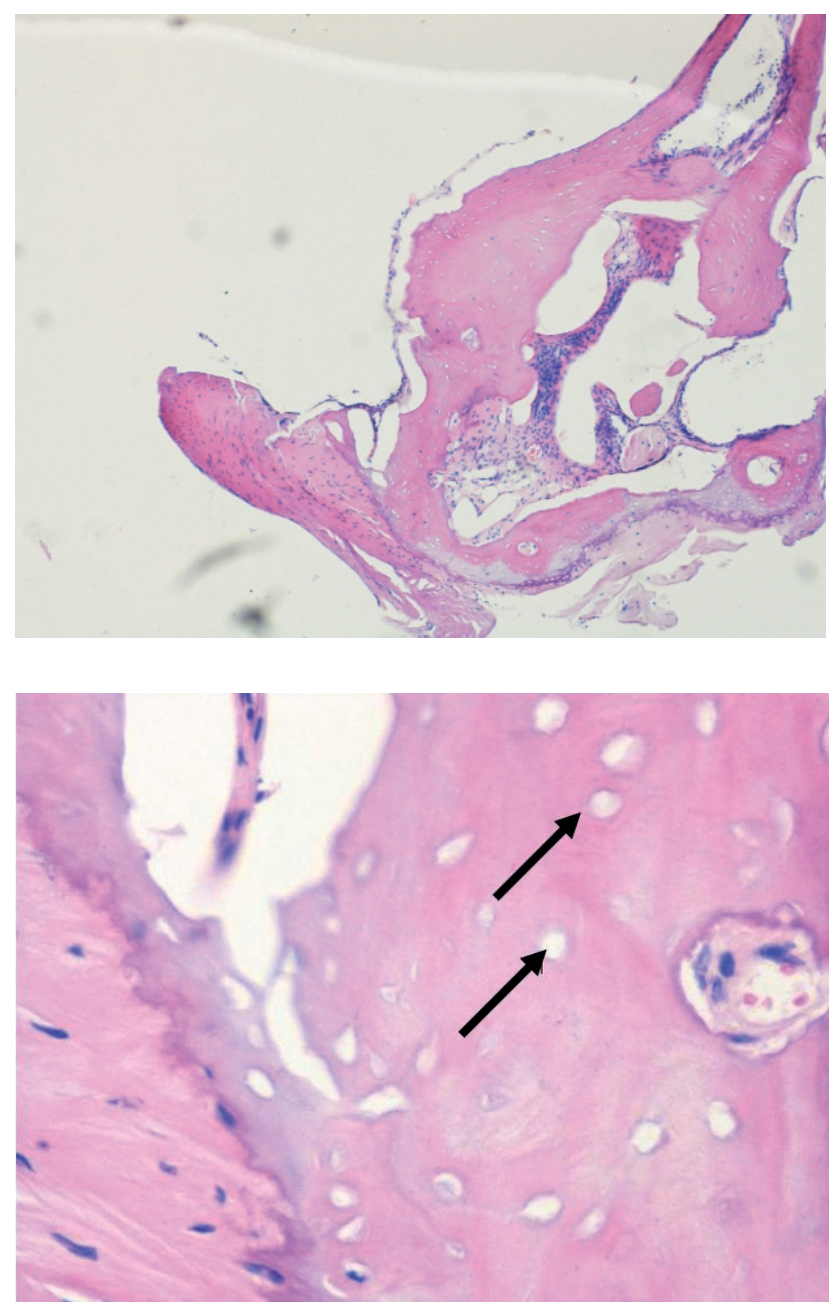

Fig. 5: Histological finding of avascular necrosis of osteosclerotic stapes suprastructure with cellular and vascular reduction (a) magnify $10 \times$ and b) magnifay $40 \times$ Arrows show empty lacunae in dead bone, without substitution and healing response 
result confirmed finding of avascular necrosis. Clinical evaluation after one month was excellent improvement of patient's hearing. Patient's hearing is much better and tinnitus still exists on very low intensity, much more quiet than before surgery. Control pure-tone audiometry showed closed gap on his right ear, but there was still mild sensorineural hearing loss (Fig. 6).

\section{Discussion}

The cause of otosclerosis is still unknown (6). Etiopathogenesis of otosclerosis was based of histopathological analysis of the removed stapes footplate in earlier researches, but nowadays all researches are based on molecular biology of otosclerosis (13). Persistent measles virus infection of the otic capsule is supposed to be one of the etiologic factors in otosclerosis. Chronic viral antigen expression on the surface of infected cells can induce a secondary autoimmune reaction against the otic capsule $(7,8)$. Epidemiological studies show significant decrease of otosclerosis in population vaccinated against the measles virus (14). Some other researches do not support the hypothesis that persistent measles virus infection is involved in pathoetiology of otosclerosis $(4,9)$.

What could happen in the case of high grades otosclerosis (grade IV otosclerosis) with avascular necrosis? Otosclerotic process develops for many years, accumulates osteosclerotic masses on one side (around the otic capsule) and reduces blood supply in bone tissue on other side (in the stapes crura). In the case of avascular necrosis, the healing process is usually ineffective and the bone tissues break down faster than the body can repair them. If left untreated, the disease progresses, the bone collapses and breaks down at a point stapes crura Doing Valsalva test patient could exceed minor displacement of stapes crura with better position of broken stapes crura in a point of pathological fracture of stapes crura, which made possible better mobility of ossicular chain and temporary improved sound transition. Otosclerotic process usually develops on stapes footplate and spreads around oval window, to the inner ear and promontory. Only in high grades otosclerosis, otosclerotic process spreads to one or both stapes crura, leading to avascular necrosis and break of stapes crura. That was happened in this case, according to our opinion.

The diagnosis of otosclerosis is made by detailed anamnesis and conventional audiologic evaluation. Diagnosing otosclerosis with avascular necrosis and displacement of stapes crura is not easy. Diagnosis of avascular necrosis of big bones is made with x-ray, bone scintigraphy, MRI and CT scan. It is also possible in case of stapes involvement, but since the stapes is the smallest bone of human body it can be complicated. Imaging of the stapes is a challenge because of the very small size of its components, the head, the crura, and the footplate. Oblique axial plane could enhance the $\mathrm{CT}$ analysis of the stapes and provide useful biometric landmarks in pathologic conditions (5). High-resolution computed tomography scan (HRCT scan) is good for the precise anatomical details in the middle ear (10). We established the diagnosis of otosclerosis with avascular necrosis of stapes crura during surgery work and with histopathological finding of stapes suprastructure. MSCT scan of temporal bones was not preformed in this case, because of a fact that technical possibilities of our MSCT scan is not so sophisticated and this kind of minor displacement or fracture of stapes crura in the middle ear could not be established.

\section{Conclusion}

Surgery is still only therapeutic treatment for otosclerosis and for otosclerosis with avascular necrosis of stapes crura to. Diagnosing otosclerosis is succsesable with hearing tests, clinical and radiological findings. Diagnosing complicated cases of otosclerosis, like otosclerosis with avascular necrosis and displacement of stapes crura, is not easy. HRCT scan can be useful to determine small damages of ossicualar chain in the middle ear On the other hand explorative surgery provides us good information for precise diagnosis of otosclerosis. The most important point of this case report is actually for surgeons to think about some other morbidly which corespond with otosclerosis. Histopathology finding can help to explain etiopathogenesis of otosclerosis. Surgery with stapedotomy and stapes prosthesis implantation in a case of otosclerosis with avascular necrosis of stapes crura improves patient hearing and can decrease tinnitus.

\section{References}

1. Arnold W. Some remarks on the histopathology of otosclerosis. Adv Otorhinolaryngol. 2007; 65: 25-30.

2. Cureoglu S, Schachern PA, Ferlito A, Rinaldo A, Tsuprun V, Paparella MM. Otosclerosis: etiopathogenesis and histopathology. Am J Otolaryngol. 2006 Sep-Oct; 27(5): $334-40$

3. Gerlinger I, Tóth M, Lujber L, Szanyi I, Móricz P, Somogyvári K, Németh A, Ráth G, Pytel J, Mann W. Necrosis of the long process of the incus following stapes surgery: new anatomical observations. Laryngoscope. 2009 Apr; 119(4): $721-6$.

4. Grayeli AB, Palmer P, Tran Ba Huy P, Soudant J, Sterkers O, Lebon P, Ferrary E. J Clin. No evidence of measles virus in stapes samples from patients with otosclerosis. Microbiol. 2000 Jul; 38(7): 2655-60.

5. Henrot P, Iochuma S, Batcha T, Coffinetc L, Bluma A, Rolanda J. Current Multiplanar Imaging of the Stapes. AJNR 2005; 26: 2128-2133.

6. Karosi T, Sziklai I. Etiopathogenesis of otosclerosis. Eur Arch Otorhinolaryngol. 2010 Sep; 267(9): 1337-49.

7. Karosi T, Kónya J, Szabó LZ, Sziklai I. Measles virus prevalence in otosclerotic stapes footplate samples. Otol Neurotol. 2004 Jul; 25(4): 451-6.

8. Karosi T, Kónya J, Szabó LZ, Sziklai I. Measles virus prevalence in otosclerotic foci. Adv Otorhinolaryngol. 2007; 65: 93-106.

9. Komune N, Ohashi M, Matsumoto N, Kimitsuki T, Komune S, Yanagi Y. No evidence for an association between persistent MV infection and otosclerosis among Japanese patients. J Clin Microbiol. 2012 Jan 11. [Epub ahead of print]

10. Lagleyre S, Sorrentino T, Calmels MN, Shin YJ, Escudé B, Deguine O, Fraysse B. Reliability of high-resolution CT scan in diagnosis of otosclerosis. Otol Neurotol. 2009 Dec; 30(8): 1152-9.

11. Lemound J, Eckardt A, Kokemüller H, von See C, Voss PJ, Tavassol F, Rücke M, Rana M, Gellrich NC. Bisphosphonate-associated osteonecrosis of the mandible: reliable soft tissue reconstruction using a local myofascial flap. Clin Oral Investig. 2011 Aug 5. [Epub ahead of print] 
12. Mangham CA Jr. Long-term impact of incus necrosis on revision stapes surgery: incus versus malleus reconstruction. Otol Neurotol. 2009 Dec; 30(8): $1145-51$

13. McKenna MJ, Kristiansen AG. Molecular biology of otosclerosis. Adv Otorhinolaryngol. 2007; 65: 68-74.
14. Niedermeyer HP, Arnold W. Otosclerosis and measles virus - association or causation? ORL J Otorhinolaryngol Relat Spec. 2008; 70(1): 63-9.

15. Singh S, Salib RJ, Oates J. Traumatic fracture of the stapes suprastructure following minor head injury. The Journal of Laryngology \& Otology 2002; 116 : 457-459.

Received: 20/05/2012

Accepted in revised form: 15/11/2012

\section{Corresponding author:}

Milan Erdoglija, Clinic for Ear, Nose and Throat, Military Medical Academy, Belgrade, Serbia; e-mail: milan.erdoglija (a)gmail.com 